\title{
Beliefs of UK Transplant Recipients about Living Kidney Donation and Transplantation: Findings from a Multicentre Questionnaire-Based Case-Control Study
}

\author{
Pippa K. Bailey ${ }^{1,2, *(\mathbb{D})}$, Fergus J. Caskey ${ }^{1,2}$, Stephanie MacNeill ${ }^{1}$, Charles Tomson ${ }^{3}$ (D), \\ Frank J. M. F. Dor ${ }^{4}$ and Yoav Ben-Shlomo ${ }^{1}$ (D) \\ 1 Population Health Sciences, Bristol Medical School, University of Bristol, Bristol BS8 2PS, UK; \\ fergus.caskey@bristol.ac.uk (F.J.C.); stephanie.macneill@bristol.ac.uk (S.M.); \\ y.ben-shlomo@bristol.ac.uk (Y.B.-S.) \\ 2 Southmead Hospital, North Bristol NHS Trust, Bristol BS10 5NB, UK \\ 3 The Newcastle upon Tyne Hospitals NHS Foundation Trust, Newcastle upon Tyne NE7 7DN, UK; \\ ctomson@doctors.org.uk \\ 4 Imperial College Healthcare NHS Trust, London W12 0HS, UK; frank.dor@nhs.net \\ * Correspondence: pippa.bailey@bristol.ac.uk; Tel.: +44-177-331-4522
}

Received: 8 November 2019; Accepted: 19 December 2019; Published: 21 December 2019

\begin{abstract}
Differing beliefs about the acceptability of living-donor kidney transplants (LDKTs) have been proposed as explaining age, ethnic and socioeconomic disparities in their uptake. We investigated whether certain patient groups hold beliefs incompatible with LDKTs. This questionnaire-based case-control study was based at 14 hospitals in the United Kingdom. Participants were adults transplanted between 1 April 2013 and 31 March 2017. LDKT recipients were compared to deceased-donor kidney transplant (DDKT) recipients. Beliefs were determined by the direction and strength of agreement with ten statements. Multivariable logistic regression was used to investigate the association between beliefs and LDKT versus DDKT. Sex, age, ethnicity, religion, and education were investigated as predictors of beliefs. A total of 1240 questionnaires were returned ( $40 \%$ response). DDKT and LDKT recipients responded in the same direction for $9 / 10$ statements. A greater strength of agreement with statements concerning the 'positive psychosocial effects' of living kidney donation predicted having an LDKT over a DDKT. Older age, Black, Asian and Minority Ethnic (BAME) group ethnicity, and having a religion other than Christianity were associated with greater degree of uncertainty regarding a number of statements, but there was no evidence that individuals in these groups hold strong beliefs against living kidney donation and transplantation. Interventions should address uncertainty, to increase LDKT activity in these groups.
\end{abstract}

Keywords: living kidney donation; living-donor kidney transplantation; beliefs; inequity

\section{Introduction}

Living-donor kidney transplantation offers the best treatment in terms of life-expectancy and quality of life [1-6] for most people with kidney failure. The healthcare costs associated with living-donor kidney transplants (LDKTs) are less than for dialysis or deceased-donor kidney transplants (DDKTs) [7,8]. The medium-term risks of donating a kidney are small [9-12] and the quality of life of donors returns to pre-donation levels after donation [13,14].

Only 20\% of those listed on the UK national transplant waiting list receive an LDKT each year [15]. Certain individuals with renal disease appear to be disadvantaged: people from Black and Asian ethnic 
groups in the UK are less likely to receive an LDKT when compared to White people with kidney disease $[16,17]$. Socioeconomic deprivation is also associated with reduced access to living-donor kidney transplantation [16,17]. Older people with kidney disease are less likely to receive an LDKT when compared to younger patients [17], and women are less likely to receive an LDKT when compared to men $[18,19]$. Ensuring equity in living-donor kidney transplantation has been highlighted as a UK and international research priority by patients and clinicians [20-22]. Differing beliefs in the acceptability of living kidney donation and transplantation have been proposed as a possible explanation for the observed differences in access $[17,23,24]$.

In this questionnaire-based case-control study, we compared the beliefs of LDKT and DDKT recipients about the acceptability of living kidney donation and transplantation. We investigated whether beliefs about living-donor kidney transplantation were associated with an individual's sex, age, ethnicity, religion and education. We aimed to identify groups with beliefs against living-donor kidney transplantation, that may explain the observed disparities in the uptake of LDKTs.

\section{Experimental Section}

\subsection{Participants}

The study was based at 14 UK hospitals (listed in Supplementary Methods). We wanted to investigate beliefs about living-donor kidney transplantation specifically, and not kidney transplantation in general. Therefore, we did not invite people with Chronic Kidney Disease or those on dialysis to participate, as some of these individuals may have held beliefs against transplantation in general, as opposed to living-donor kidney transplantation specifically. We obtained from each site an anonymised list of all individuals who received kidney transplants between 1 April 2013 and 31 March 2017, stratified by LDKT and DDKT status. Individuals aged $<18$ years at the time of transplantation, and individuals lacking mental capacity according to the Mental Capacity Act 2005, were excluded. We performed stratified random sampling using Stata 15 [25] to select, on average, 110 LDKTs and 110 DDKTs from each site, weighted by the number of transplants performed annually at each study site. Sex and 5-year age group strata-matched sampling was used to ensure a similar sample distribution by age and sex. The case-control study was designed to detect a 7-point difference in a continuous measure of patient activation (analysis of this variable not presented here) between LDKT cases and DDKT controls with $90 \%$ power, assuming a 5\% significance level. The calculation indicated that 170 patients would be needed, and that, therefore, a total of 944 would be needed to allow analyses stratified by Index of Multiple Deprivation rank quintile and allow for $10 \%$ missing data. This sample size allows for the detection of a far smaller difference (0.16 Standard Deviation) for a dichotomous exposure or between $6-8 \%$ for a categorical outcome [26].

\subsection{Questionnaire Content and Survey Tools}

Paper questionnaires were mailed by post to participants by research collaborators at the study sites. Questionnaires were accompanied by a patient information sheet, an invitation letter and a return postage paid envelope. A website-address was provided so that participants could complete the questionnaire online if preferred. Non-responders were sent a second questionnaire after 4-6 weeks. Anonymised data were extracted from returned paper questionnaires at the University of Bristol and uploaded onto a secure REDCap database [27].

Transplant beliefs were assessed using questions developed by Stothers et al. [28,29]. In development, the questions were reviewed by three expert focus groups, then evaluated in a pilot study to test content reliability and validity [28]. Test-retest analysis was reported as demonstrating excellent internal consistency, and there was no evidence of 'skew' or 'halo' effects (an overall perception/feeling of satisfaction that influences all responses rather than allowing a thoughtful consideration of each individual question) [28]. Participants were asked to read ten statements describing a belief regarding living-donor kidney transplantation (Box 1). These included statements 
regarding the acceptability of receiving a donated kidney, coercion or pressure on family to donate, rewards for the donor, required closeness of relationship, the subsequent effect on relationship, beliefs about recipients asking family to donate, donation from offspring to parents, and the risks of donation. Participants were asked to tick one of the following options: (i) Strongly disagree, (ii) Disagree, (iii) Agree, (iv) Strongly agree, (v) Don't know.

Box 1. Belief statements.

1. It is morally acceptable to take a kidney from a healthy person.

2. Donors often agree to donate due to feelings of guilt or family pressure.

3. Donating a kidney is a rewarding experience for the live donors.

4. Donating a kidney to someone requires an extremely close personal relationship.

5. A living-donor kidney transplant may strengthen the relationship between the donor and recipient.

6. Approaching a potential donor who then says no will change the relationship between the two people.

7. Asking someone to donate makes the recipient seem selfish.

8. It is acceptable for a parent to receive a kidney from his/her child (over 18 years old).

9. Decisions about donation should be made by the donor alone. The recipient should not ask for a kidney.

10. Since the donor operation is not risk free, someone who needs a kidney transplant should wait for a kidney from someone who has died.

Questionnaires assessed participant demographics as indicated in Box 2.

Box 2. Participant demographic data collected.

- Sex

Male; Female

- $\quad 10$-year age group

10-19 years; $20-29$ years; $30-39$ years; $40-49$ years; $50-59$ years; $60-69$ years; $70-79$ years; $80-89$ years

- $\quad$ Religion

No religion; Christian; Muslim; Jewish; Hindu; Sikh; Buddhism

- $\quad$ Socioeconomic position

No formal education; Primary school; Secondary school; Vocational/Technical; University—undergraduate; University-postgraduate; Other

- $\quad$ Ethnicity coded using the UK's Office for National Statistics 2011 census categories [30]

White;

Asian/Asian British;

Black/African/Caribbean/Black British;

- Mixed/Multiple (White and Black Caribbean, White and Black African, Any other Mixed/Multiple ethnic background);

Other (Arab, Any other ethnic group)

\subsection{Statistical Analysis}

We compared demographic characteristics between DDKT and LDKT recipients using chi ${ }^{2}$ tests. The proportion of DDKT and LDKT recipients selecting each level of agreement with a belief statement was calculated and initially compared using $\mathrm{chi}^{2}$ tests. We used multivariable logistic regression to look at the association of transplant type (LDKT versus DDKT) with a recipient's agreement with a belief statement. For the multivariable logistic regression, the response options were coded 1-4 
( 1 = strongly disagree, $2=$ disagree, $3=$ agree, $4=$ strongly agree $)$ with 'Don't know' coded as missing. For each belief statement we ran an unadjusted model and one adjusted for potential confounders. We specified, a priori, potential confounders including sex, age, education level, ethnicity and religion. We used robust standard errors to account for clustering within renal centres. Statistical analyses were performed in Stata 15 [25].

Basic descriptive statistical tests ( $\mathrm{chi}^{2}$ tests) then were performed to look for differences in response (agreement $=$ strongly agreed and agreed; disagreement $=$ strongly disagreed and disagreed $;$ and don't know) across different patient demographic groups. For these analyses, age was dichotomised into age $<60$ years and age $\geq 60$ years, ethnicity into White, Black, Asian and Minority Ethnic (BAME) groups, education into university education or no university education, and religion divided into three categories: no religion, Christianity, or other religion. Small numbers of respondents from certain ethnic groups and from religions other than Christianity or none limited subgroup analysis. Small numbers and single participant responders in some groups risked identification: we were therefore required to combine Islam, Hinduism, Judaism, Buddhism, and Sikhism as 'religions other than Christianity' for analysis.

\subsection{Ethical Approval and Consent}

We received NHS Research Ethics Committee (REC) (REC reference 17/LO/1602) and Health Research Authority (HRA) approval. A consent form formed the first page of the questionnaire. The study was funded by a Kidney Research UK Project Grant (RP_028_20170302). The clinical and research activities being reported are consistent with the Principles of the Declaration of Istanbul as outlined in the 'Declaration of Istanbul on Organ Trafficking and Transplant Tourism'.

\section{Results}

A total of 1240 questionnaires were returned from 3103 patients (40\% response). Participant characteristics are reported in Table 1.

LDKT recipients were more likely to respond than DDKT recipients ( $46 \%$ vs. $34 \%$ ) and women were more likely to respond than men ( $43 \%$ vs. $37 \%$ ) (Table S1). However, the study participants were a population representative sample (Table S2). Overall, the proportion of missing data was small ( $<3 \%$ for belief questions and $<10 \%$ for all demographic variables) (Supplementary Missing data).

\subsection{Comparison of LDKT and DDKT Recipients}

DDKT recipients expressed greater uncertainty than LDKT recipients regarding all belief statements, with a greater proportion of DDKT than LDKT recipients selecting 'Don't know' for every question (Table 2).

The direction of belief for DDKT and LDKT recipients was the same for nine statements (Table 2). The majority of both DDKT and LDKT recipients agreed with the statements: (1) It is morally acceptable to take a kidney from a healthy person; (3) Donating a kidney is a rewarding experience for live donors; (5) A living-donor kidney transplant may strengthen the relationship between the donor and recipient; (8) It is acceptable for a parent to receive a kidney from his/her child (over 18 years old); (9) Decisions about donation should be made by the donor alone. The recipient should not ask for a kidney. The majority of both DDKT and LDKT recipients disagreed that: (4) Donating a kidney to someone requires an extremely close personal relationship; (10) Since the donor operation is not risk free, someone who needs a kidney transplant should wait for a kidney from someone who has died. For these seven statements, DDKT and LDKT recipients who indicated that they had a belief (rather than did not know) reported the same direction of belief but for all questions a greater proportion of LDKT recipients indicated a stronger belief than DDKTs.

No difference between DDKT and LDKT recipients was found with either direction or strength of belief with respect to Statement (3) - 'Asking someone to donate makes the recipient seem selfish'. Statement (6)-'Approaching a potential donor who then says no will change the relationship between 
the two people' - was associated with the greatest uncertainty for all participants; $36 \%$ of DDKT recipients and 34\% of LDKT recipients selecting 'Don't know' for this question.

DDKT and LDKT recipients differed in the direction of their belief with respect to only one statement. For statement (2) - Donors often agree to donate due to feelings of guilt or family pressure'-the majority of LDKT recipients disagreed whilst DDKT recipients were split between disagreement, agreement and not knowing (Table 2).

\subsection{Predictors of Case-Control Status}

The strength of agreement with seven belief statements predicted case-control status, even after adjustment for potential confounders (Table 3). A greater level of agreement with statements 1,3,5, and 8 predicted being an LDKT over a DDKT recipient. These statements concern the 'acceptability' of living donation and transplantation, and its 'positive effects' ('rewarding experience' and 'strengthening relationship'). A greater level of disagreement with statements 2, 6 and 10 predicted being an LDKT over a DDKT recipient. These statements relate to beliefs about individuals experiencing 'pressure to donate' and the 'risks/negative impacts of living donation'.

\subsection{Participant Characteristics and Beliefs (Table S3a-e)}

\subsubsection{Sex}

For only one of the ten statements, responses from women and men differed. The majority of women and men agreed with Statement 8 -'It is acceptable for a parent to receive a kidney from his/her child (over 18 years old)' - but a greater proportion of women disagreed compared to men (14\% versus $8 \%$, chi ${ }^{2} p$-value $<0.001$ across all categories of agreement).

\subsubsection{Age}

For four of the ten statements, older respondents indicated greater uncertainty by selecting 'Don't

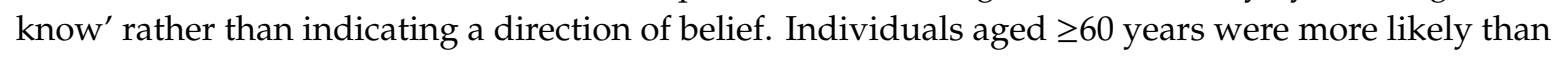
individuals aged $<60$ years to answer 'Don't know' for statement (2)-'Donors often agree to donate due to feelings of guilt or family pressure' ( $36 \%$ versus $24 \%$, chi ${ }^{2} p$-value $<0.001$ across all categories of agreement), statement (5)-'A living-donor kidney transplant may strengthen the relationship between the donor and recipient' ( $23 \%$ versus $16 \%$, chi ${ }^{2}$-value 0.02 across all categories of agreement), statement (6) -'Approaching a potential donor who then says no will change the relationships between the two people' ( $41 \%$ versus $31 \%$, chi $^{2} p$-value $<0.001$ across all categories of agreement), and statement (7) - 'Asking someone to donate makes the recipient seem selfish' ( $32 \%$ versus $18 \%$, chi ${ }^{2} p$-value $<0.001$ across all categories of agreement).

For one statement, statement (9)-'Decisions about donation should be made by the donor alone. The recipient should not ask for a kidney' - the direction of belief differed with age. People aged $\geq 60$ years were much more likely to agree compared to people aged $<60$ years $\left(73 \%\right.$ versus $57 \%$, chi ${ }^{2}$ $p$-value $<0.001$ across all categories of agreement). 
Table 1. Participant characteristics by case-control status ${ }^{\text {a }}$.

\begin{tabular}{|c|c|c|c|c|}
\hline \multicolumn{2}{|c|}{ Characteristics } & \multirow{2}{*}{$\begin{array}{c}\text { Cases }^{\mathrm{b}} \text { (LDKTs) } n=\mathbf{6 7 2} \\
382(57)\end{array}$} & \multirow{2}{*}{$\frac{\text { Controls }^{\mathbf{b}} \text { (DDKTs) } n=\mathbf{5 6 5}}{322(57)}$} & \multirow[t]{2}{*}{$\mathrm{Chi}^{2}$ Comparing Cases and Controls } \\
\hline \multirow{3}{*}{ Sex } & Male & & & \\
\hline & Female & $279(42)$ & $235(42)$ & \multirow[t]{2}{*}{$p=0.95$} \\
\hline & Missing & $11(2)$ & $8(1)$ & \\
\hline \multirow{7}{*}{ Age (years) } & $20-29$ & $47(7)$ & $27(5)$ & \multirow{7}{*}{$p=0.39$} \\
\hline & $30-39$ & 80 (12) & $57(10)$ & \\
\hline & $40-49$ & $106(16)$ & $102(18)$ & \\
\hline & $50-59$ & $178(27)$ & $153(27)$ & \\
\hline & $60-69$ & $167(25)$ & $132(23)$ & \\
\hline & $>70$ & $77(12)$ & $79(14)$ & \\
\hline & Missing & $17(3)$ & $15(3)$ & \\
\hline \multirow{6}{*}{ Ethnicity } & White & $581(87)$ & $445(79)$ & \multirow{6}{*}{$p=0.005$} \\
\hline & Asian & $38(6)$ & $41(7)$ & \\
\hline & Black/African/Caribbean & $19(3)$ & $39(7)$ & \\
\hline & Mixed/Multiple & $5(0.7)$ & $5(0.9)$ & \\
\hline & Other & $10(2)$ & $14(3)$ & \\
\hline & Missing & $19(3)$ & $21(4)$ & \\
\hline \multirow{5}{*}{ Religion } & No religion & $191(28)$ & $144(26)$ & \multirow{5}{*}{$p=0.01$} \\
\hline & Christian & $402(60)$ & $315(56)$ & \\
\hline & Muslim & $10(2)$ & $11(2)$ & \\
\hline & Other religions ${ }^{c}$ & $37(6)$ & $56(10)$ & \\
\hline & Missing & $22(3)$ & $39(7)$ & \\
\hline \multirow{7}{*}{ Highest level of education } & No formal education/Primary school & $10(2)$ & $20(4)$ & \multirow{7}{*}{$p=0.03$} \\
\hline & Secondary school & $202(30)$ & $191(34)$ & \\
\hline & Vocational/Technical & $171(26)$ & $143(25)$ & \\
\hline & University-undergraduate & $145(22)$ & $98(17)$ & \\
\hline & University-postgraduate & $73(11)$ & $46(8)$ & \\
\hline & Other & $33(5)$ & $24(4)$ & \\
\hline & Missing & $38(6)$ & $43(8)$ & \\
\hline
\end{tabular}

${ }^{a}$ The three participants for whom transplant type/case-control status was missing are excluded from this table. ${ }^{\mathrm{b}}$ Percentages may not total $100 \%$ due to figures being presented to the nearest whole number. ${ }^{\mathrm{C}}$ Hindu, Jewish, Sikh, Buddhist and Other combined due to single participant responders in some groups risking identification. 
Table 2. Beliefs about living donation and living-donor kidney transplantation.

\begin{tabular}{|c|c|c|c|c|c|c|c|}
\hline Belief Statement & Transplant Type & Strongly Disagree $n(\%)$ & Disagreen $n(\%)$ & Agreen $n(\%)$ & Strongly Agree $n(\%)$ & Don't Know $n(\%)$ & $\mathrm{Chi}^{2} p$-Value \\
\hline \multirow{2}{*}{ 1. It is morally acceptable to take a kidney from a healthy person. } & DDKT $^{a}$ & $8(2)$ & $22(4)$ & $293(53)$ & $172(31)$ & $52(10)$ & \multirow{2}{*}{$<0.001$} \\
\hline & LDKT $^{\text {a }}$ & $24(4)$ & $11(2)$ & $252(39)$ & $340(52)$ & $28(4)$ & \\
\hline \multirow{2}{*}{ 2. Donors often agree to donate due to feelings of guilt or family pressure. } & DDKT & $63(11)$ & $172(31)$ & $117(21)$ & $22(4)$ & $177(32)$ & \multirow{2}{*}{$<0.001$} \\
\hline & LDKT & $134(20)$ & $262(40)$ & $81(12)$ & $9(1)$ & $170(26)$ & \\
\hline \multirow{2}{*}{ 3. Donating a kidney is a rewarding experience for the live donors. } & DDKT & $6(1)$ & $5(0.9)$ & $260(47)$ & $158(29)$ & $123(22)$ & \multirow{2}{*}{$<0.001$} \\
\hline & LDKT & $11(2)$ & $4(0.6)$ & $269(41)$ & $314(48)$ & $60(9)$ & \\
\hline \multirow{2}{*}{$\begin{array}{l}\text { 4. Donating a kidney to someone requires an extremely close } \\
\text { personal relationship. }\end{array}$} & DDKT & $78(14)$ & $286(52)$ & $79(14)$ & $47(9)$ & $62(11)$ & \multirow{2}{*}{0.004} \\
\hline & LDKT & $121(18)$ & $331(50)$ & $110(17)$ & $59(9)$ & $38(6)$ & \\
\hline \multirow{2}{*}{$\begin{array}{l}\text { 5. A living-donor kidney transplant may strengthen the relationship } \\
\text { between the donor and recipient. }\end{array}$} & DDKT & $8(2)$ & $55(10)$ & $254(46)$ & $77(14)$ & $158(29)$ & \multirow{2}{*}{$<0.001$} \\
\hline & LDKT & $13(2)$ & $65(10)$ & $314(48)$ & $198(30)$ & $69(11)$ & \\
\hline \multirow{2}{*}{$\begin{array}{l}\text { 6. Approaching a potential donor who then says no will change the } \\
\text { relationship between the two people. }\end{array}$} & DDKT & $47(9)$ & $185(34)$ & $85(16)$ & $33(6)$ & $200(36)$ & \multirow{2}{*}{0.001} \\
\hline & LDKT & $91(14)$ & $235(36)$ & $96(15)$ & $14(2)$ & $222(34)$ & \\
\hline \multirow{2}{*}{ 7. Asking someone to donate makes the recipient seem selfish. } & DDKT & $45(8)$ & $204(37)$ & $120(22)$ & $41(8)$ & $139(25)$ & \multirow{2}{*}{0.45} \\
\hline & LDKT & $68(10)$ & $256(39)$ & $145(22)$ & $38(6)$ & $151(23)$ & \\
\hline \multirow{2}{*}{$\begin{array}{l}\text { 8. It is acceptable for a parent to receive a kidney from his/her child } \\
\text { (over } 18 \text { years old). }\end{array}$} & DDKT & $23(4)$ & $45(8)$ & $292(53)$ & $106(19)$ & $86(16)$ & \multirow{2}{*}{0.002} \\
\hline & LDKT & $17(3)$ & $40(6)$ & 365 (56) & $169(26)$ & $68(10)$ & \\
\hline \multirow{2}{*}{$\begin{array}{l}\text { 9. Decisions about donation should be made by the donor alone. } \\
\text { The recipient should not ask for a kidney. }\end{array}$} & DDKT & 19 (4) & $112(20)$ & $203(37)$ & $127(23)$ & 90 (16) & \multirow{2}{*}{$<0.001$} \\
\hline & LDKT & $42(6)$ & $121(18)$ & $213(32)$ & $220(33)$ & $62(9)$ & \\
\hline \multirow{2}{*}{$\begin{array}{l}\text { 10. Since the donor operation is not risk free, someone who needs } \\
\text { a kidney transplant should wait for a kidney from someone who has died. }\end{array}$} & DDKT & $87(16)$ & $311(56)$ & $52(9)$ & $10(2)$ & $92(17)$ & \multirow{2}{*}{$<0.001$} \\
\hline & LDKT & $265(40)$ & $336(51)$ & $5(0.8)$ & $8(1)$ & $44(7)$ & \\
\hline
\end{tabular}

${ }^{\text {a }}$ DDKT = deceased-donor kidney transplant; LDKT = living-donor kidney transplant. 
Table 3. Strength of agreement and likelihood of being an LDKT recipient over a DDKT recipient.

\begin{tabular}{|c|c|c|c|}
\hline \multirow{2}{*}{ Belief Statement } & \multicolumn{2}{|c|}{$\begin{array}{l}\text { Association between Agreement with Statement and } \\
\text { Likelihood of Being an LDKT Recipient over a DDKT Recipient }\end{array}$} & \multirow[t]{2}{*}{ Interpretation } \\
\hline & Unadjusted OR $(95 \%$ CI) & Adjusted OR $^{\text {a }}(95 \% \mathrm{CI})$ & \\
\hline 1. It is morally acceptable to take a kidney from a healthy person. & $1.47(1.26-1.71)$ & $1.47(1.29-1.68)$ & $\begin{array}{l}\text { Agreement with statement predicts } \\
\text { being an LDKT recipient }\end{array}$ \\
\hline 2. Donors often agree to donate due to feelings of guilt or family pressure. & $0.56(0.45-0.70)$ & $0.57(0.45-0.73)$ & $\begin{array}{l}\text { Disagreement with statement predicts } \\
\text { being an LDKT recipient }\end{array}$ \\
\hline 3. Donating a kidney is a rewarding experience for the live donors. & $1.56(1.24-1.94)$ & $1.42(1.13-1.78)$ & $\begin{array}{l}\text { Agreement with statement predicts } \\
\text { being an LDKT recipient }\end{array}$ \\
\hline $\begin{array}{l}\text { 4. Donating a kidney to someone requires an extremely close } \\
\text { personal relationship. }\end{array}$ & $0.97(0.84-1.13)$ & $0.94(0.79-1.12)$ & \\
\hline $\begin{array}{l}\text { 5. A living-donor kidney transplant may strengthen the relationship } \\
\text { between the donor and recipient. }\end{array}$ & $1.42(1.20-1.68)$ & $1.45(1.21-1.74)$ & $\begin{array}{l}\text { Agreement with statement predicts } \\
\text { being an LDKT recipient }\end{array}$ \\
\hline $\begin{array}{l}\text { 6. Approaching a potential donor who then says no will change the } \\
\text { relationship between the two people. }\end{array}$ & $0.69(0.62-0.78)$ & $0.62(0.55-0.71)$ & $\begin{array}{l}\text { Disagreement with statement predicts } \\
\text { being an LDKT recipient }\end{array}$ \\
\hline 7. Asking someone to donate makes the recipient seem selfish. & $0.88(0.75-1.02)$ & $0.86(0.71-1.04)$ & \\
\hline $\begin{array}{l}\text { 8. It is acceptable for a parent to receive a kidney from his/her child } \\
\text { (over } 18 \text { years old). }\end{array}$ & $1.31(1.10-1.56)$ & $1.29(1.04-1.60)$ & $\begin{array}{l}\text { Agreement with statement predicts } \\
\text { being an LDKT recipient }\end{array}$ \\
\hline $\begin{array}{l}\text { 9. Decisions about donation should be made by the donor alone. } \\
\text { The recipient should not ask for a kidney. }\end{array}$ & $1.09(0.98-1.21)$ & $1.05(0.95-1.19)$ & \\
\hline $\begin{array}{l}\text { 10. Since the donor operation is not risk free, someone who needs a kidney } \\
\text { transplant should wait for a kidney from someone who has died. }\end{array}$ & $0.36(0.27-0.47)$ & $0.38(0.27-0.54)$ & $\begin{array}{l}\text { Disagreement with statement predicts } \\
\text { being an LDKT recipient }\end{array}$ \\
\hline
\end{tabular}




\subsubsection{Education}

For two of the ten statements, a greater proportion of those who did not go to university disagreed with the statement compared to those who did: statement (5) -'A living-donor kidney transplant may strengthen the relationship between the donor and recipient' (13\% vs. $\left.7 \%, \mathrm{chi}^{2} p=0.008\right)$, and statement (6)-'Approaching a potential donor who then says no will change the relationship between the two people' (49\% versus $42 \%$, chi $^{2} p$-value 0.03 ). For statement (9)—'Decisions about donation should be made by the donor alone. The recipient should not ask for a kidney'-individuals without a university degree were more likely to agree than those with $\left(66 \%\right.$ versus $58 \%$, chi ${ }^{2} p$-value 0.04$)$.

Individuals without a university degree indicated greater uncertainty with respect to statement (7) - 'Asking someone to donate makes the recipient seem selfish' — with a higher proportion selecting 'Don't know' compared to those with a university degree ( $26 \%$ versus $18 \%$, chi ${ }^{2} p$-value 0.01$)$.

\subsubsection{Ethnicity}

The majority of both white and non-white individuals agreed with statement (1) regarding the moral acceptability of taking a living-donor transplant $(89 \%$ and $81 \%)$, but of the remainder, non-white individuals were more likely to select 'Don't know' than white individuals (13\% versus $6 \%$, chi ${ }^{2}$ $p$ value $=0.002$ ). Statement $(10)$-'Since the donor operation is not risk free, someone who needs a kidney transplant should wait for a kidney from someone who has died'-generated the greatest ethnic difference in opinion: non-white individuals were less likely to say they disagreed with this statement (69\% versus $85 \%$ ) and more likely to indicate that they did not know ( $21 \%$ versus $9 \%$, chi ${ }^{2}$ $p<0.001)$.

\subsubsection{Religion}

For statement (1) - It is morally acceptable to take a kidney from a healthy person' —a greater proportion of people from the 'Other religions' group selected 'Don't know' (13\%) compared to those of no religion (5\%) and Christians $(7 \%)\left(\mathrm{Chi}^{2} \mathrm{p}=0.01\right)$. Similarly, for statement (3)-'Donating a kidney is a rewarding experience for the live donors'-individuals from the group comprising religions other than Christianity were less likely to agree, and more likely to select 'Don't know' (24\%) compared to those of no religion $(19 \%)$ and Christians $(11 \%)\left(\mathrm{Chi}^{2} p<0.001\right)$. For statement $(10)-$ 'Since the donor operation is not risk free, someone who needs a kidney transplant should wait for a kidney from someone who has died'-a smaller proportion of people in the 'Other religions' group said that they disagreed with this statement (65\%) compared to people of no religion $(89 \%)$ or Christians $(89 \%)$, and a greater proportion selected 'Don't know' (24\%) compared to Christians (10\%) and people with no religion $(8 \%)\left(\mathrm{chi}^{2} p<0.001\right)$.

For statement (6)-'Approaching a potential donor who then says no will change the relationship between the two people' - a slightly greater proportion of Christians (49\%) disagreed with the statement compared those of 'Other religions' $(43 \%)$ or none $(42 \%)\left(\mathrm{chi}^{2} p=0.008\right)$.

\section{Discussion}

In this questionnaire-based case-control study, we compared the beliefs of LDKT and DDKT recipients about the acceptability of living kidney donation and transplantation. We found no evidence that DDKT recipients hold strong beliefs against living-donor kidney transplantation. Rather, DDKT recipients hold similar beliefs to LDKT recipients, but report less conviction and greater uncertainty. We did not investigate the source of beliefs in this questionnaire, but it would be interesting to investigate whether the greater uncertainty in the DDKT respondents influences or reflects the beliefs of family members and potential donors. Uncertainty may reflect differing or conflicting beliefs within a family regarding the acceptability of living-donor kidney transplantation.

We aimed to identify groups with beliefs against living-donor kidney transplantation that may explain observed sex, age, ethnic and socioeconomic disparities in the uptake of LDKTs. Overall, 
we did not find any evidence of significant difference in the direction of belief with sex, age, ethnicity, religion or education. This suggests that inequality in LDKT uptake associated with sex, age, ethnic, or socioeconomic position is not explained by disproportionately high numbers of individuals in these groups holding beliefs that are incompatible with living-donor kidney transplantation.

BAME group ethnicity and having a religious affiliation other than Christianity were both associated with greater uncertainty regarding a number of belief statements. BAME individuals were particularly uncertain as to whether one should wait for a DDKT, given that living kidney donation is not risk free. Uncertainty regarding organ donation and transplantation has previously been reported in qualitative research amongst certain ethnic and religious groups, attributed specifically to uncertainty regarding religious edicts [31,32]. One qualitative study from the Netherlands identified a lack of awareness about the 'official' position of an individual's religion regarding living organ donation within communities, and confusion due to differing interpretations of religious texts [32]. Research from the USA has shown that, amongst church-attending African-American individuals without kidney disease, 37\% disagreed with living donation [33], and members of the clergy were more likely to express reservations about living donation than deceased donation ( $33.3 \%$ versus $16.7 \%$ ) [33]. These studies suggest that faith leaders might play an important educational role, that their opinion might be influential, and that clarity over the position of the religion on living-donation needs to be made explicit [32-34]. To this end, during the preparation of this manuscript, a new fatwa clarifying Islamic approval of living and deceased organ donation and transplantation was published in the UK [35].

Older people reported greater uncertainty in their beliefs about the impact of donation on the family, and whether asking is selfish on the recipient's part. Older people have been reported as being unhappy to accept an organ from a younger living donor [36,37], in part due to parents believing they should protect their children from harm [36,37]. This belief regarding the acceptability of living-donor kidney transplantation might be influenced by clinicians: research from the USA has suggested that eligible older people with kidney disease are less likely to be encouraged to seek a transplant by their nephrologists [38].

Our findings suggest that the majority of DDKT recipients believe living kidney donation and living-donor kidney transplantation are acceptable, appropriate and justifiable. The majority of demographic groups believe that there are benefits from LDKTs to both the donor and the recipient. Given these beliefs, it suggests that there is capacity to increase LDKT activity in the UK. There should be no assumption that people of certain groups (BAME or older people) have strong beliefs against an LDKT-but rather, any uncertainty should be taken as an opportunity to engage in discussion. Attitudes towards living kidney donation are often open to change and, accordingly, can be influenced [39]. Conversations with religious leaders may help to overcome specific uncertainties regarding a particular religion's position on living donation [34,35].

The belief statements in this study were first developed and used in a Canadian population [29]. LDKT recipients and wait-listed patients surveyed in Canada were found to have the same direction of response as LDKT recipients and DDKT recipients in the UK for all statements except for Statements (4) and (10). For Statement (4)—'Donating a kidney to someone requires an extremely close personal relationship' - 69\% Canadian LDKT recipients agreed or strongly agreed with this statement, compared to $26 \%$ of UK LDKT recipients. For statement (10)—'Since the donor operation is not risk free, someone who needs a kidney transplant should wait for a kidney from someone who has died'-a greater proportion of UK DDKT recipients disagreed with this statement when compared to Canadian wait-listed patients $(72 \%$ versus $52 \%)$. These differences may reflect transplant practice and beliefs changing over time, since the Canadian study was undertaken over 15 years earlier. However, these differences may in part explain why the UK's LDKT activity is greater than Canada's [40], and this requires further investigation.

In our study, statement (10)-'Since the donor operation is not risk free, someone who needs a kidney transplant should wait for a kidney from someone who has died'-generated the 
most difference in opinion; therefore, how beliefs will change with the UK's move to an opt-out deceased-donation law in 2020 will need to be investigated.

This was a large, multicentre study. To our knowledge, this is the first quantitative study to investigate beliefs about living-donor kidney transplantation amongst transplant recipients. The questionnaire was evaluated in cognitive interviews prior to use, validated and then piloted [26]. The proportion of missing data was small. However, the study has limitations: (i) Although our response rate was reasonable for an unincentivized postal survey, and compares to the response rate of other postal surveys in the UK [41,42] and that of previous a previous European transplant survey [43], there is a risk of self-selection bias. We have reported in our results that our population appeared population representative (Table S2). In addition, we compared our findings to those from the Access to Transplantation and Transplant Outcome Measures (ATTOM) study (which had 72\% participation), and found the same effect sizes between socioeconomic position and likelihood of an LDKT (see Table S4) providing further evidence our sample is fairly representative of the total population of such patients. (ii) A total of $14 \%$ of participants were from BAME groups-this is not a surprising finding as in the UK between 2013 and 2017 BAME individuals comprised 17\% of LDKT recipients and $27 \%$ of LDKT kidney transplant recipients [44], but this did prevent the analysis of individual ethnic groups (e.g., Asian, Black, Chinese).

The questionnaire was administered to LDKT and DDKT transplant recipients, both of whom have experienced transplantation; thus in the analyses examining the relationship between beliefs and transplant type, one might expect responses to be subject to a range of cognitive biases, including justifying their decision, and endowment effects. However, evidence against a significant endowment effect on the direction of belief includes the finding that the majority of DDKT recipients expressed positive beliefs about living donation and transplantation. Were there significant endowment effects, we would not have expected the majority of DDKT recipients to express positive beliefs about LDKTs. Cognitive biases do not explain the differences in beliefs between different demographic groups.

\section{Conclusions}

The majority of both DDKT and LDKT recipients across all demographic groups reported holding positive beliefs about living donation and transplantation. This encouraging finding suggests that, at least on the part of the transplant candidate, beliefs that are incompatible with LDKT are not a major barrier to living-donor transplantation in the UK, and that there is capacity to increase LDKT activity.

Supplementary Materials: The following are available online at http://www.mdpi.com/2077-0383/9/1/31/s1, Supplementary Methods; Table S1. Responders and non-responders, Table S2. Responders compared to national denominator population, Supplementary Missing Data, Table S3a. Difference in beliefs with participant sex, Table S3b. Difference in beliefs with participant age, Table S3c. Difference in beliefs with participant education, Table S3d. Difference in beliefs with participant ethnicity, Table S3e. Difference in beliefs with participant religion, Table S4. Comparison with participants in ATTOM study.

Author Contributions: Conceptualization, P.K.B., Y.B.-S., C.T.; Methodology, P.K.B., Y.B.-S., S.M.; Software, P.K.B.; Formal analysis, P.K.B., S.M.; Investigation, P.K.B.; Data curation, P.K.B.; Writing-original draft preparation, P.K.B.; Writing-review and editing, P.K.B., S.M., F.J.M.F.D., Y.B.-S., C.T., F.J.C.; Supervision, Y.B.-S., C.T., F.J.C.; Project administration, P.K.B.; Funding acquisition, P.K.B. All authors have read and agreed to the published version of the manuscript.

Funding: This report is independent research arising from a Kidney Research UK Project Grant (Reference RP_028_20170302). Neither Kidney Research UK nor the University of Bristol had any role in study design, data collection, analysis, interpretation, manuscript preparation of the decision to submit the report for publication. YB-S is the equity theme lead for the NIHR Collaboration for Leadership in Applied Health Research and Care West (CLAHRC West) at University Hospitals Bristol NHS Foundation Trust. CLAHRC West is part of the NIHR and is a partnership between University Hospitals Bristol NHS Foundation Trust and the University of Bristol. The views expressed in this publication are those of the authors and not necessarily those of the funder.

Acknowledgments: The authors would like to thank all the study participants, the participating centre research nurses and coordinators (Hugh Murtagh, Nina Bleakley, Mary Dutton, Kulli Kuningas, Cecilio Bing Andujar, Ann-Marie O'Sullivan, Nicola Johnson, Kieron Clark, Thomas Walters, Mary Quashie-Akponeware, Jane Turner, Gillian Curry, Hannah Beer, Lynn.D Langhorne, Sarah Brand, Maria Weetman, Molly Campbell, Megan Bennett, Sharirose Abat, and Agyapong Kwame Ansu) and the local collaborators who facilitated the study (Sarah Heap, 
Mysore Phanish, Shafi Malik, Aisling Courtney, Adnan Sharif, Nicholas Torpey, Refik Gökmen, Michael Picton, Linda Bisset, Edward Sharples, and Simon Curran).

Conflicts of Interest: The authors declare no conflict of interest. The funders had no role in the design of the study; in the collection, analyses, or interpretation of data; in the writing of the manuscript, or in the decision to publish the results.

\section{References}

1. Cecka, J. Living donor transplants. Clin. Transplant. 1995, 10, 363-377.

2. Terasaki, P.; Cecka, J.; Gjertson, D.; Takemoto, S. High survival rates of kidney transplants from spousal and living unrelated donors. N. Engl. J. Med. 1995, 333, 333-336. [CrossRef] [PubMed]

3. Laupacis, A.; Keown, P.; Pus, N.; Krueger, H.; Ferguson, B.; Wong, C.; Muirhead, N. A study of the quality of life and cost-utility of renal transplantation. Kidney Int. 1996, 50, 235-242. [CrossRef] [PubMed]

4. Cecka, J. The OPTN/UNOS Renal Transplant Registry. Clin. Transpl. 2005, 1-16.

5. Roodnat, J.I.; van Riemsdijk, I.C.; Mulder, P.G.H.; Doxiadis, I.; Claas, F.H.J.; Ijzermans, J.N.M.; van Gelder, T.; Weimar, W. The superior results of living-donor renal transplantation are not completely caused by selection or short cold ischemia time: A single-center, multivariate analysis. Transplantation 2003, 75, 2014-2018. [CrossRef]

6. Statistics and Clinical Audit: NHS Blood and Transplant Organ Donation and Transplantation Activity Report 2013/14. Available online: https://nhsbtdbe.blob.core.windows.net/umbraco-assets-corp/1286/activity_ report_2013_14.pdf (accessed on 20 December 2019).

7. Barnieh, L.; Manns, B.; Klarenbach, S.; McLaughlin, K.; Yilmaz, S.; Hemmelgarn, B. A description of the costs of living and standard criteria deceased donor kidney transplantation. Am. J. Transplant. 2011, 11, 478-488. [CrossRef]

8. Smith, C.; Woodward, R.; Cohen, D.; Singer, G.; Brennan, D.; Lowell, J.; Howard, T.; Schnitzler, M. Cadaveric versus living donor kidney transplantation: A Medicare payment analysis. Transplantation 2000, 69, 311-314. [CrossRef]

9. Maggiore, U.; Budde, K.; Heemann, U.; Hilbrands, L.; Oberbauer, R.; Oniscu, G.; Pascual, J.; Schwartz Sorensen, S.; Viklicky, O.; Abramowicz, D. Long-term risks of kidney living donation: Review and position paper by the ERA-EDTA DESCARTES working group. Nephrol. Dial. Transplant. 2017, 32, 216-223. [CrossRef]

10. Muzaale, A.D.; Massie, A.B.; Wang, M.; Montgomery, R.; McBride, M.; Wainright, J.; Segev, D. Risk of end-stage renal disease following live kidney donation. JAMA 2014, 311, 579-586. [CrossRef]

11. Massie, A.; Muzaale, A.; Luo, X.; Chow, E.; Locke, J.; Nguyen, A.; Henderson, M.; Snyder, J.; Segev, D. Quantifying Postdonation Risk of ESRD in Living Kidney Donors. J. Am. Soc. Nephrol. 2017, 28, 2749-2755. [CrossRef]

12. Segev, D.L.; Muzaale, A.D.; Caffo, B.S.; Mehta, S.; Singer, A.; Taranto, S.; McBride, M.; Montgomery, R. Perioperative mortality and long-term survival following live kidney donation. JAMA 2010, 303, 959-966. [CrossRef] [PubMed]

13. Lumsdaine, J.A.; Wray, A.; Power, M.J.; Jamieson, N.V.; Akyol, M.; Andrew Bradley, J.; Forsythe, J.L.R.; Wigmore, S.J. Higher quality of life in living donor kidney transplantation: Prospective cohort study. Transpl. Int. 2005, 18, 975-980. [CrossRef] [PubMed]

14. Johnson, E.; Anderson, J.; Jacobs, C.; Suh, G.; Humar, A.; Suhr, B.; Kerr, S.; AJ, M. Long-term follow-up of living kidney donors: Quality of life after donation. Transplantation 1999, 67, 717-721. [CrossRef] [PubMed]

15. Statistics and Clinical Audit: NHS Blood and Transplant Organ Donation and Transplantation Activity Report 2017/18. Available online: https://nhsbtdbe.blob.core.windows.net/umbraco-assets-corp/12300/transplantactivity-report-2017-2018.pdf (accessed on 20 December 2019).

16. Udayaraj, U.; Ben-Shlomo, Y.; Roderick, P.; Casula, A.; Dudley, C.; Collett, D.; Ansell, D.; Tomson, C.; Caskey, F. Social Deprivation, Ethnicity, and Uptake of Living Kidney Donor Transplantation in the United Kingdom. Transplantation 2012, 93, 610-616. [CrossRef] [PubMed]

17. Wu, D.; Robb, M.; Watson, C.; Forsythe, J.; Tomson, C.; Cairns, J.; Roderick, P.; Johnson, R.; Ravanan, R.; Fogarty, D.; et al. Barriers to living donor kidney transplantation in the United Kingdom: A national observational study. Nephrol. Dial. Transplant. 2017, 32, 890-900. [CrossRef] [PubMed] 
18. Kayler, L.; Rasmussen, C.; Dykstra, D.; Ojo, A.; Port, F.; Wolfe, R.; Merion, R. Gender imbalance and outcomes in living donor renal transplantation in the United States. Am. J. Transplant. 2003, 3, 452-458. [CrossRef] [PubMed]

19. Ojo, A.; Port, F. Influence of race and gender on related donor renal transplantation rates. Am. J. Kidney Dis. 1993, 22, 835-841. [CrossRef]

20. Lentine, K.; Kasiske, B.; Levey, A.; Adams, P.; Alberú, J.; Bakr, M.; Gallon, L.; Garvey, C.; Guleria, S.; Li, P.; et al. KDIGO Clinical Practice Guideline on the Evaluation and Care of Living Kidney Donors. Transplantation 2017, 101, S1-S109. [CrossRef]

21. Karet Frankl, F.; Coward, R.; Gallagher, H.; Hilton, R.; Loud, F.; Modi, K.; Ormandy, P.; Woolf, A. UK Renal Research Strategy; UK Kidney Research Consortium: Cambridgeshire, UK, 2016; Available online: https://kidneyresearchuk.org/wp-content/uploads/2019/02/KR9501-UKRRS-Booklet-V8-WEB.pdf (accessed on 20 December 2019).

22. Rodrigue, J.; Kazley, A.; Mandelbrot, D.; Hays, R.; LaPointe Rudow, D.; Baliga, P. Living Donor Kidney Transplantation: Overcoming Disparities in Live Kidney Donation in the US-Recommendations from a Consensus Conference. Clin. J. Am. Soc. Nephrol. 2015, 10, 1687-1695. [CrossRef]

23. Martínez-Alarcón, L.; Ríos, A.; Conesa, C.; Alcaraz, J.; González, M.J.; Ramírez, P.; Parrilla, P. Attitude of kidney patients on the transplant waiting list toward related-living donation. A reason for the scarce development of living donation in Spain. Clin. Transplant. 2006, 20, 719-724. [CrossRef]

24. Zimmerman, D. The influence of socio-demographic factors, treatment perceptions and attitudes to living donation on willingness to consider living kidney donor among kidney transplant candidates. Nephrol. Dial. Transplant. 2006, 21, 2569-2576. [CrossRef] [PubMed]

25. StataCorp 2017; Release 15; Stata Statistical Software; StataCorp LLC: College Station, TX, USA, 2017.

26. Bailey, P.; Tomson, C.; Ben-Shlomo, Y. What factors explain the association between socioeconomic deprivation and reduced likelihood of live-donor kidney transplantation? A questionnaire based pilot case-control study. BMJ Open 2016, 6. [CrossRef]

27. Harris, P.; Taylor, R.; Thielke, R.; Payne, J.; Gonzalez, N.; Conde, J. Research electronic data capture (REDCap)-a metadata-driven methodology and workflow process for providing translational research informatics support. J. Biomed. Inform. 2009, 42, 377-381. [CrossRef] [PubMed]

28. Stothers, L.; Gourlay, W.; Liu, L. Attitudes and predictive factors for live kidney donation: A comparison of live kidney donors versus nondonors. Kidney Int. 2005, 67, 1105-1111. [CrossRef] [PubMed]

29. Gourlay, W.; Stothers, L.; Liu, L. Attitudes and predictive factors for live kidney donation in British Columbia. A comparison of recipients and wait-list patients. Can. J. Urol. 2005, 12, 2511-2520. [PubMed]

30. O'Brien, R.; Potter-Collins, A. 2011 Census Analysis: Ethnicity and Religion of the non-UK Born Population in England and Wales: 2011; Office for National Statistics: South Wales, UK, 2015. Available online: https://www.ons.gov.uk/peoplepopulationandcommunity/culturalidentity/ethnicity/ articles/2011censusanalysisethnicityandreligionofthenonukbornpopulationinenglandandwales/2015-06-18 (accessed on 20 December 2019).

31. Irving, M.; Tong, A.; Jan, S.; Cass, A.; Rose, J.; Chadban, S.; Allen, R.; Craig, J.; Wong, G.; Howard, K. Factors that influence the decision to be an organ donor: A systematic review of the qualitative literature. Nephrol. Dial. Transplant. 2012, 27, 2526-2533. [CrossRef] [PubMed]

32. Ismail, S.; Massey, E.; Luchtenburg, A.; Claassens, L.; Zuidema, W.; Busschbach, J.; Weimar, W. Religious attitudes towards living kidney donation among Dutch renal patients. Med. Health Care Philos. 2012, 15, 221-227. [CrossRef]

33. Locke, J.; Qu, H.; Shewchuk, R.; Mannon, R.; Gaston, R.; Segev, D.; Mannon, E.; Martin, M. Identification of strategies to facilitate organ donation among African Americans using the nominal group technique. Clin. J. Am. Soc. Nephrol. 2015, 10, 286-293. [CrossRef]

34. Afzal Aghaee, M.; Dehghani, M.; Sadeghi, M.; Khaleghi, E. Awareness of Religious Leaders' Fatwa and Willingness to Donate Organ. Int. J. Organ Transplant. Med. 2015, 6, 158-164.

35. New Fatwa to Clarify Lslamic Position on Organ Donation; NHS Blood and Transplant: Filton, UK, 19 June 2019; Available online: https://www.organdonation.nhs.uk/get-involved/news/new-fatwa-published-to-clarifyislamic-position-on-organ-donation/ (accessed on 20 December 2019). 
36. Hanson, C.; Chadban, S.; Chapman, J.; Craig, J.; Wong, G.; Ralph, A.; Tong, A. The Expectations and Attitudes of Patients with Chronic Kidney Disease Toward Living Kidney Donor Transplantation: A Thematic Synthesis of Qualitative Studies. Transplantation 2015, 99, 540-554. [CrossRef]

37. Gordon, E. “They don't have to suffer for me": Why dialysis patients refuse offers of living donor kidneys. Med. Anthropol. Q. 2001, 15, 245-267. [CrossRef] [PubMed]

38. Gordon, E.; Sehgal, A. Patient-nephrologist discussions about kidney transplantation as a treatment option. Adv. Ren. Replace. Ther. 2000, 7, 177-183. [CrossRef] [PubMed]

39. Hilhorst, M.; Kranenburg, L.; Busschbach, J. Should health care professionals encourage living kidney donation? Med. Health Care Philos. 2007, 10, 81-90. [CrossRef] [PubMed]

40. International Registry in Organ Donation and Transplantation (IRODaT) Database. Available online: http://www.irodat.org/?p=database (accessed on 20 December 2019).

41. Robb, K.; Gatting, L.; Wardle, J. What impact do questionnaire length and monetary incentives have on mailed health psychology survey response? Br. J. Health Psychol. 2017, 22, 671-685. [CrossRef] [PubMed]

42. Harrison, S.; Henderson, J.; Alderdice, F.; Quigley, M. Methods to increase response rates to a population-based maternity survey: A comparison of two pilot studies. BMC Med. Res. Methodol. 2019, 19, 65. [CrossRef] [PubMed]

43. Slaats, D.; Lennerling, A.; Pronk, M.; van der Pant, K.; Dooper, I.; Wierdsma, J.; Schrauwers, C.; Maple, H.; van de Wetering, J.; Weimar, W.; et al. Donor and Recipient Perspectives on Anonymity in Kidney Donation From Live Donors: A Multicenter Survey Study. Am. J. Kidney Dis. 2018, 71, 52-64. [CrossRef] [PubMed]

44. Organ Donation and Transplantation Data for Black, Asian and Minority Ethnic (BAME) Communities. NHS Blood and Transplant. Report for 2017/2018 (1 April 2013-31 March 2018). Available online: https://nhsbtdbe.blob.core.windows.net/umbraco-assets-corp/12048/bame-organ-donationand-transplantation-data-2017-18.pdf (accessed on 20 December 2019).

(C) 2019 by the authors. Licensee MDPI, Basel, Switzerland. This article is an open access article distributed under the terms and conditions of the Creative Commons Attribution (CC BY) license (http://creativecommons.org/licenses/by/4.0/). 